\title{
Description of Pintomyia (Pifanomyia) paleotrichia, a Miocene period new species from the Dominican Republic (Diptera: Psychodidae: Phlebotominae)
}

\author{
José Dilermando Andrade Filho/ ${ }^{+}$, Reginaldo Peçanha Brazil*, Alda Lima Falcão, \\ Eunice A Bianchi Galati**
}

\begin{abstract}
Laboratório de Leishmanioses, Centro de Pesquisas René Rachou-Fiocruz, Av. Augusto de Lima 1715, 30190-002 Belo Horizonte, MG, Brasil *Departamento de Bioquímica e Biologia Molecular, Instituto Oswaldo Cruz-Fiocruz, Rio de Janeiro, RJ, Brasil

**Departamento de Epidemiologia, Faculdade de Saúde Pública, Universidade de São Paulo, São Paulo, SP, Brasil
\end{abstract}

A new fossil species of phlebotomine sandflies is described from Dominican amber based in one specimen. Pintomyia (Pifanomyia) paleotrichia sp. nov. is distinguished from the other extant and extinct species by aspects of paramere and the basal tuft of bristles in the gonocoxite.

Key words: Pintomyia (Pifanomyia) paleotrichia - amber - fossil - Phlebotominae

Phlebotomines are found in several countries, including all the known zoogeographic zones. This fact can be explained by the long evolutive history of this group of insects, that would have appeared in the Palaeozoic end of or beginning of the Mesozoic (Andrade Filho \& Brazil 2003).

In accordance with the classification proposed by Galati (1995), the genus Pintomyia Costa Lima, 1932 is constituted by two subgenera: Pintomyia s. s. and Pifanomyia Ortiz \& Scorza, 1963. This latter includes extant and extinct species (Brazil \& Andrade Filho 2002, Andrade Filho et al. 2004, 2006a, b). The extant species are found mainly in the Andean region and Central America, frequently associate with forests. The speciation of the group seems to be the result of diverse biogeographic and climatic events that had affected the flora and fauna of those regions (Bejarano et al. 2003).

A new species of sand fly is described from one fossil preserved in amber, the piece of the holotype having the following measurements: length $21 \mathrm{~mm}$; maximum width $13 \mathrm{~mm}$ and height $2 \mathrm{~mm}$. The amber piece contains two more insects: another fly and a louse. The terminology adopted follows that of McAlpine (1981) and Galati (2003) and the nomenclature of the species in accordance with Galati (1995). All the structures had been examined under an Olimpus $\mathrm{CH}-2$ optical microscope $(400 \mathrm{X})$ with measurements in micrometers.

The new species is called Pintomyia (Pifanomyia) paleotrichia, due to the large number of bristles in the gonocoxite and parameres.

Financial support: Capes, Fiocruz

${ }^{+}$Corresponding author: jandrade@cpqrr.fiocruz.br

Received 2 March 2007

Accepted 27 September 2007
Pintomyia (Pifanomyia) paleotrichia sp. nov. (Figs 1-6)

Holotype male - Total length 1610. The coloration of the insect was not possible to observe.

Head (lateral view) - Total length 178. Ratio head/ clypeus and epipharynx-labrum/head 0.62:1. Flagellomeres measuring: AIII 204; AIV 106; AV 106, AXV longer than AXVI. Interocular distance was not measured due to the lateral position of the head. Ascoids visible from AIII to AVIII; on AIII they are implanted at the same level, without basal spur and their apex not reaching the base of the subsequent flagellomere. AIII, AIV, AV with papilla; AXIV with apical papilla but absent in the flagellomeres AXI-AXIII. Papal formula 1.4.2.3.5; the palpomere measuring: 1st - 27, 2nd - 109, 3rd - 130, 4th 100,5 th -315 . Newstead's spine implanted dispersed on $3^{\text {rd }}$ palpomere, from the basal third.

Cervix - It was not possible to observe the ventrocervical sensillae.

Thorax - Presence of superior anepisternals bristles. Legs without special characters. Length of femora, tibiae, basitarsi; tarsomere II+III+IV+V: foreleg 611 , 666 , 389, 555; midleg 577, 788, 477, 588; hindleg 622 , $932,555,633$. Wing measuring 1554 of length by 355 of maximum width. Main wing indices: alpha 244; beta 189; gamma 222; delta 16; R5 921.

Abdomen - Gonocoxite 211 length and 57 wide, presenting a basal tuft of approximately 13 long bristles. However, as they are overlapped it was not possible to identify their implantation point, neither to which gonocoxite they belong. For the arrangement of these bristles we deduced they are implanted in only one gonocoxite. Gonostyle: length 81, presenting four spines, being one apical, one external superior, one external inferior implanted in the middle of the structure and an internal one implanted in the basal third. The pre-apical seta was not observed. Paramere with evident concavity in the median part of its dorsal margin, where it is narrower than the apical one. Dorsal margin with numerous fine and long se- 


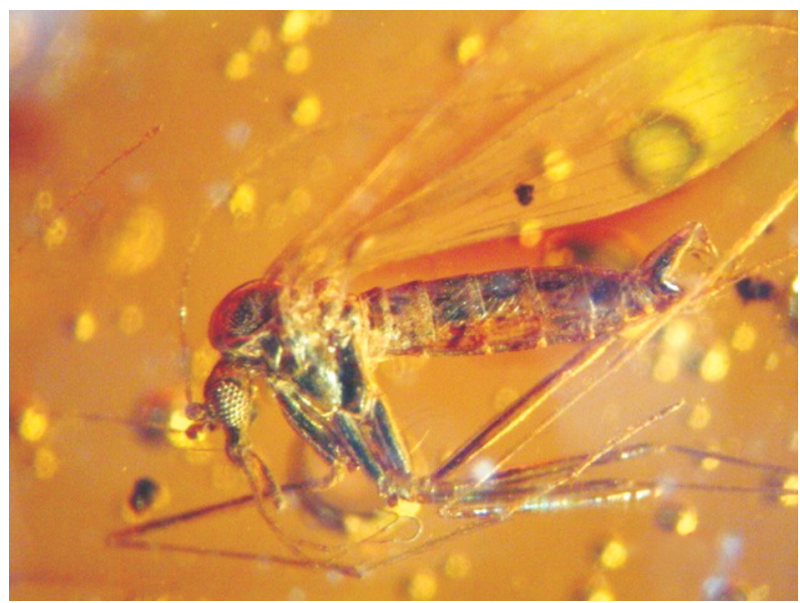

Fig. 1: Pintomyia paleotrichia sp. nov. (holotype male) (40X).
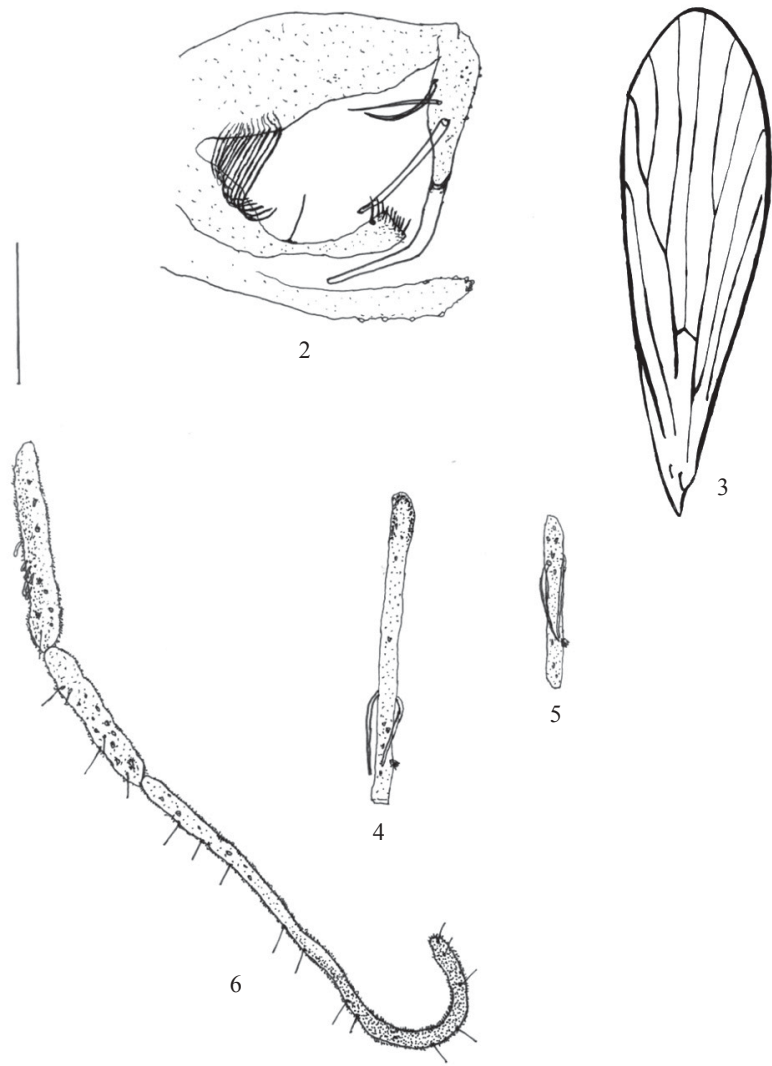

Figs 2-6: Pintomyia paleotrichia sp. nov. (holotype male). 2: terminalia; 3: wing; 4: AIII; 5: AV; 6: palpomeres 3, 4, and 5. Bar $=100 \mu \mathrm{m}$.

tae on base and short and a little thicker ones on apex; one more evident spiniform seta is present on the narrowed median part. Lateral lobe simple, measuring 233 long by 14 wide. It was not possible to visualize the genital pump, filaments, as well as the aedeagus.
Type-material - Holotype male, Dominican Republic, northern Santiago, specimen in amber from the midMiocene period, deposited in the phlebotomine sand fly collection of the Instituto René Rachou (Fundação Oswaldo Cruz), Belo Horizonte, MG, Brazil.

\section{TAXONOMIC DISCUSSION}

The morphological characteristics described allow us to include this sand fly in the genus Pintomyia, and the absence of spines in the posterior femur, in the subgenus Pifanomyia. The gonostyle with two external spines and the internal one implanted in the basal part of the article, the basal tuft of long bristles on the gonocoxite allow us to include $P$. (Pi.) paleotrichia sp. nov. in the series townsendi, despite the presence of the papilla on AV that in absent in the extant.

The paramere of $P$. (Pi.) paleotrichia sp. nov. with the evident concavity and apex wider than its median part reminds those of the extant species $P$. (Pi.) torvida (Young Morales \& Ferro, 1994) and P. (Pi.) longiflocosa (Osorno-Mesa, Morales, Osorno \& Hoyos, 1970). However the isolated setae on its median part of the dorsal margin and this latter recovered with several setae on its basal and apical regions distinguish it easily from these two extant species. Some species of Evandromyia, cortelezzii series and tupinambai of Barrettomyia subgenus show also morphological aspects similar to the new species, mainly in relation to the terminalia. They are easily distinguished by having a pointed bump in the pre-apical region of the ventral edge in this structure, while P. (Pi.) paleotrichia sp. nov. does not have such structure.

In relation to the fossil species of the subgenus Pifanomyia, P. paleotrichia sp. nov. are easily separated of Pintomyia falcaorum Brazil \& Andrade Filho, 2002 and Pintomyia brazilorum Andrade Filho, Galati \& Falcão, 2006, by the presence of a dense tuft of bristles in the gonocoxite. Pintomyia paleotowsendi Andrade Filho, Falcão, Galati \& Brazil, 2006, also has a tuft of bristles in the gonocoxite (Andrade Filho et al. 2006a) however both species can be separated by the larger number of bristles in P. paleotrichia sp. nov. and by aspects of paramere, that present many setae in apical region of the new species.

Recently other five fossil sandfly species have been described from Dominican Republic using the nomenclature in accordance with the Young and Duncan (1994)'s classification (Peñalver \& Grimaldi 2005). Two of those species show four spines in the gonostyle, Lutzomyia filipalpis Peñalver \& Grimaldi, 2005 and Lutzomyia schleei Peñalver \& Grimaldi, 2005, however both do not have any basal tuft of bristles in the gonocoxite that clearly distinguish them from $P$. (Pi.) paleotrichia sp. nov.

With the description of this species, the fossil sand fly fauna of the Neotropical region are now composed by 11 described species, one from Mexico (Quate 1963) and 10 from Dominican Republic.

\section{REFERENCES}

Andrade Filho JD, Brazil RP 2003. Relationships of new word phlebotomine sand flies (Diptera: Psychodidae) based on fossil evidence. Mem Inst Oswaldo Cruz 98 (Suppl. I): 145-149. 
Andrade Filho JD, Falcão AL, Brazil RP 2004. A new phlebotomine fossil species Trichopygomyia killickorum sp. n. (Diptera: Psychodidae), found in the Dominican Republic amber. Parasite 11: 71-73.

Andrade Filho JD, Falcão AL, Galati EAB, Brazil RP 2006a. Pintomyia (Pifanomyia) paleotowsendi, a new sand fly from the Miocene amber of Dominican Republic (Diptera: Psychodidae: Phlebotominae). Mem Inst Oswaldo Cruz 101 (Suppl. II): 57-58.

Andrade Filho JD, Galati EAB, Falcão AL 2006b. Description of Pintomyia (Pifanomyia) brazilorum sp. nov. a new fossil species from the Dominican Republic (Diptera: Psychodidae: Phlebotominae). Mem Inst Oswaldo Cruz 101: 141-142.

Bejarano EE, Rojas W, Uribe S, Vélez ID 2003. Sistemática de especies de Lutzomyia del grupo verrucarum Theodor, 1965 (Diptera: Psychodidae). Biomédica 23: 87-102.

Brazil RP, Andrade Filho JD 2002. Description of Pintomyia (Pifanomyia) falcaorum sp. n. (Diptera: Psychodidae:
Phlebotominae), a fossil sand fly from Dominican Amber. Mem Inst Oswaldo Cruz 97: 501-503.

Galati EAB 1995. Phylogenetic systematic of Phlebotominae (Diptera, Psychodidae) with emphasis on American groups. Bol Dir Malariol San Amb 35 (Suppl. I): 133-142.

Galati EAB 2003. Classificação de Phlebotominae. In EF Rangel, R Lainson (eds), Flebotomíneos do Brasil, Fiocruz, Rio de Janeiro, p. 23-51.

McAlpine JF 1981. Morphology and terminology - Adults. In JF McAlpine, BV Peterson, GE Shelwell, HJ Teskey, JR Vockeroth, DM Wood (eds), Manual of Nearctic Diptera, Ottawa, Research Branch Agriculture Canada, Monography 27, Vol. 1, p. 9-63.

Peñalver E, Grimaldi D 2005. Assemblages of mammalian hair and blood-feeding midges (Insecta: Diptera: Psychodidae: Phlebotominae) in Miocene amber. Trans R Soc Edin: Earth Sci 96: 177-195.

Quate LW 1963. Fossil Psychodidae in Mexican amber, part 2 Diptera: Insecta J Paleontol 37: 110-118. 
